\title{
A Review of Research on Tapered Roller Bearings
}

\author{
Authors
}

Mr. R. R. Kulkarni' ${ }^{1}$, Dr. P. R. Kulkarni ${ }^{2}$

${ }^{1}$ Department of Mechanical Engineering, Walchand Institute of Technology, Ashok Chowk,

Solapur-413006

${ }^{2}$ Head of the Mechanical Engineering Department, Walchand Institute of Technology, Ashok Chowk, Solapur-413006

Email: rutooooraj@gmail.comand

ABSTRACT

This paper reviews the detailed study of tapered roller bearings. The literature review is carried on design and analysis of tapered roller bearings. In this paper the recent and past developments, theories on design of rolling element bearings are presented, analysis of rolling element bearings using FEM software's are reviewed.

\section{INTRODUCTION}

A rolling-element bearing, also known as a rolling bearing is a bearing which carries a load by placing rolling elements (such as balls or rollers) between two bearing rings called races. The relative motion of the races cause the rolling elements to roll with very little rolling resistance and with little sliding. One of the earliest and best-known rolling-element bearings are sets of logs lay on the ground with a large stone block on top. As the stone is pulled, the logs roll along the ground with little sliding friction. As each $\log$ comes out the back, it is moved to the front where the block then rolls on to it. It is possible to imitate such a bearing by placing several pens or pencils on a table and placing an item on top of them. A rolling element rotary bearing uses a shaft in a much larger hole, and cylinders called "rollers" tightly fill the space between the shaft and hole. As the shaft turns, each roller acts as the logs in the above example. However, since the bearing is round, the rollers never fall out from under the load.

Rolling-element bearings have the advantage of a good tradeoff between cost, size, weight, carrying capacity, durability, accuracy, friction, and so on. Other bearing designs are often better on one specific attribute, but worse in most other attributes, although fluid bearings can sometimes simultaneously outperform on carrying capacity, durability, accuracy, friction, rotation rate and sometimes cost. Only plain bearings are used as widely as rolling-element

\section{bearings.}

A large majority of rotating machineries rely on rolling element bearings (REBs). Due to necessity and vital contribution to most rotating machineries, the requirements on the bearings have become stricter everyday. The bearings provide relative positioning and rotating freedom while usually transmitting a load between shaft and housing. Rotating machineries are complex and have numerous components that could potentially fail. An analysis should be made to identify the bearings defects before they become catastrophically fail with the associated downtime costs and significant damage to other parts of rotating machineries. The vibration spectrum analysis is a popular technique among others such as time domain and time frequency domain for tracking machinery operating conditions. Intensive research has been done in recent years for the REBs defect diagnosis to ensure the performance and extend the bearing life.

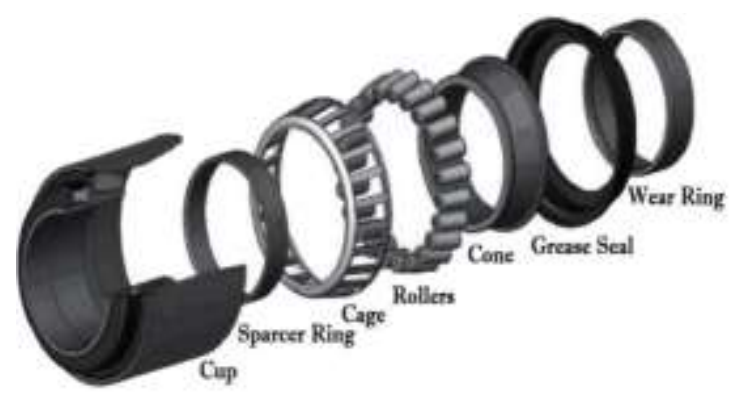




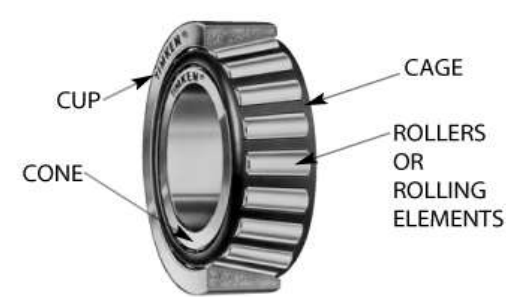

Fig. Disassembled view of cartridge tapered roller bearing

\section{LITERATURE REVIEW}

Hamrock, et.al. (1983) in their brief status report on bearing technology and present and near-term future problems that warrant research support is presented. For rolling element bearings a material with improved fracture toughness, life data in the low A region, a comprehensive failure theory verified by life data and incorporated into dynamic analyses, and an improved corrosion resistant alloy are perceived as important needs.

Schwarz, et.al.(2006) said the purpose of this paper is to present a description of a twin tapered roller bearing assembly and the measurement systems for carrying out an experimental analysis on the thermal behavior of the assembly, taking into account mainly the bearing friction torque and the operating temperatures of the shaft, bearings and housing. The results are obtained for a range of rotational speeds and loading conditions. The temperatures of the bearing are taken for the inner and the outer raceways, simultaneously with the guide flange lip/roller and contact.

Kayal, Yusuf, et.al. (2009) saidtapered roller bearings, which are also known as angularcontact bearing, are suitable for supporting radial and axial loads. The more frequent types of defects in such bearings are caused by contact fatigue in these machine components, and this examination focuses on a contact fatigue failure in a tapered rolling bearing. The examination included visual inspection, microscopic analysis (optical and scanning electron microscope), and micro hardness measurements. These measurements were conducted to help understand the failure mechanisms. Based on the results of visual examination and microstructure and fracture surface analysis, it was determined that the tapered roller bearing failed by contact fatigue that was caused by overloading of the bearing. Ebert et.al. (2010) said the aim is to outline the complex interrelation of all fundamentals with the rolling contact fatigue and the attainable bearing life. Such fundamentals include, amongst others, bearing stressing and life capability. The article shows the different types of rolling bearing stressing and the analysis of the stress distribution (principal stresses and equivalent stresses) in the material under the rolling contact area. It becomes obvious that the contamination of the bearing with foreign particles leads to a drastic reduction in bearing life. Furthermore, it demonstrates the impact of the bearing lubrication and coating as well as the effect of additives on the attainable life and wear. The article reveals the importance of the cleanliness of bearing steels as well as different types of inclusions and their effect on rolling contact fatigue. Additionally the article describes how to optimize the material properties (strength, toughness and residual stress) by the heat treatment processes. The outcome of these investigations is that endurance life of a rolling element bearing can be achieved if specific operating conditions, an adequate lubrication, good system cleanliness and specific bearing stressing are met.

Yong qi et.al.(2012) said taper roller bearings are important part of gear reducers, and their work property affects behavior of the reducers. Pre-tightening of taper- roller bearings affects both meshing contact of the gears and lubrication between the rollers and raceways of the bearings. The influence is analyzed by finite element method in this work. Firstly, a finite element model of roller bearings is established by using Reynolds equation and considering the surface roughness. Then, Stress fields in the roller and the raceway are calculated by adding load and solving, obtaining the maximum stress and strain of the bearings. Finally, effect of the pre-tightening on the work property of the bearings are analyzed by the obtained the maximum stress and strain. Guo Yi et.al.(2012), In this study, a finite element/contact mechanics model is developed for rolling element bearings with the focus of obtaining accurate bearing stiffness for a wide range of bearing types and parameters. A 
combined surface integral and finite element method is used to solve for the contact mechanics between the rolling elements and races. This model captures the time-dependent characteristics of the bearing contact due to the orbital motion of the rolling elements. A numerical method is developed to determine the full bearing stiffness matrix corresponding to two radial, one axial, and two angular coordinates; the rotation about the shaft axis is free by design. This proposed stiffness determination method is validated against experiments in the literature and compared to existing analytical models and widely used advanced computational methods. The fullypopulated stiffness matrix demonstrates the coupling between bearing radial, axial, and tilting bearing deflections.

R.K. Upadhyay et.al. (2013) stated that rolling Contact Fatigue (RCF) occurs due to the result of cyclic stress developed during operation and mechanism that involve in fretting failure of rolling element bearing. As bearing raceways of non-rotating rolling element bearings exposed to vibration or sliding oscillation false Brinelling occurs. Bearing surface due to false Brinelling tends to damage within a short period, due to cavities created on the bearing raceway. Recommendation towards enhancement of bearing life is also suggested.

TANG Zhaoping et.al. (2013) stated that through contact analysis, the changes could be showed in stress, strain, penetration, sliding distance, friction stress among the inner ring, outer ring, rolling elements and cage. Furthermore, the simulation results revealed that the computational values were consistent with theoretical values. The all showed that the model and boundary conditions were correct and rational, and it would provide a scientific basis for optimum design of rolling bearings under complicated loads.

Yan-shuang WANG et.al. (2013) said that clearance not only affects the startup torque, rotation precision and stiffness of bearing, but also affects the load distribution, loadcarrying capacity and life of bearing. A computational model in which the clearance of bearing is first included is presented for determining the contact force distribution and static load-carrying capacity of a double row four-point contact ball bearing which is subjected to the combined radial, axial and overturning moment loadings. The relation between the negative axial clearance and the contact force distribution is analyzed. The static load-carrying cyclic autocorrelation have improved the fault detection.

M. Prem Kumar et.al.(2015) stated that in the railroad industry, troubled bearings in service are primarily identified using wayside hot-box detectors (HBDs). Several bearings set-out for trending and classified as non-verified, due to no visible damage within a cone assembly. Subsequent laboratory experiments were performed to determine a minimum temperature and environment necessary to reproduce these discolorations which are mostly due to roller capacity curves are established, and the effects of the changes in negative axial clearance, curvature radius coefficient of raceway groove and initial contact angle on the static load-carrying capacity are analyzed. The results show that, with the increase in the absolute value of negative clearance, the maximum contact load decreases first and then increases. The clearance values in the range of $0.2 \mathrm{~mm}-0 \mathrm{~mm}$ have little effect on the static load-carrying capacity of bearing. With the increase in the curvature radius coefficient of raceway groove and the decrease in the initial contact angle, the static load capacity of bearing decreases.

H. Saruhan et.al.(2014)studied the vibration analysis of rolling element bearings (REBs) defects. The REBs are the most widely used mechanical parts in rotating machinery under high load and high rotational speeds. When the defect in a rolling element comes into contact with another element surface, an impact force is generated which is resulting in an impulsive response of the bearing. A defect at any element of the REB transmits to all other elements such as outer race, inner race, ball and, train cage of the bearing. The defect in rolling elements may lead to serious catastrophic consequences resulting in costly downtime. For this purpose, the vibration analysis technique which is a reliable and accurately detecting defect in the bearing elements is used. 
Shah Dipen S. et.al.(2014) said the existence of even tiny defects on the mating surfaces of the bearing components can lead to failure through passage of time. Their failure leads to economical and personal losses. The vibration monitoring technique is mostly used in the industries for health monitoring of bearings. Significant studies are available in open literature for vibration analysis of healthy and defective rolling elements bearings. Various researchers have studied the vibrations generated by bearings through theoretical model and experimentations. The researchers have developed the dynamic model of shaft bearing systems for the theoretical studies. This paper reviews different dynamic models for rolling bearing in presence and absence of local and distributed defects. Moreover, the techniques used for the improvement of fault detection have also been summarized. The signal processing techniques like wavelet transform, high frequency resonance technique (HFRT), envelope analysis and temperatures greater than $232 \mathrm{C}(450 \mathrm{~F})$ for periods of at least 4hours. Research is going on the possibility that rollers reaching such elevated temperatures without heating the bearing cup (outer race) to a temperature significant enough to trigger the HBDs. Considering the previous experimental and analytical work, a static- thermal finite element analysis (FEA) of a railroad bearing pressed onto an axle and was analyzed using ANSYS. Analysis is carried out by considering certain radial load and thrust load. Present work shows the stresses at various temperatures, fatigue life, vibration characteristics and the dynamic response of a structure under the action of time dependent loads. Also Present work evaluates the Hot Box Detector (HBD) temperature by showing the bearing safe temperature, failure temperature and stresses under cyclic loading.

Findings from literature review:

Few researches in the field of bearings have already been done.

Some researchers reported study on Ball and Roller bearings.

Rolling-element bearings have the advantage of a good tradeoff between cost, size, weight, carrying capacity, durability, accuracy, friction, and so on. Other bearing designs are often better on one specific attribute, but worse in most other attributes.

Some research has been done in the railroad industry in the bearing sector.

Cartridge tapered roller bearings are used for BOXN wagons to withstand heavy loads.

The stress analysis as well as the analysis for the load carrying capacity must be done on the existing design of cartridge tapered roller bearing to study any flaws in the design.

\section{Literature Gap:}

Analysis of rolling elements such as balls, rollers etc. is done only in few of the cases.There is a scope for detailed analysis in this section.

Only few research papers focuses on the analysis of cartridge tapered roller bearings.

Detailed stress analysis hasn't been done on the cartridge tapered roller bearings.

Stress analysis of rolling elements may be done to study the stress concentration.

\section{CONCLUSION}

From this review of research on study of Tapered roller Bearings we can conclude that Increasing bearing diameter the bearing life will increase substantially. This will increasethe subsequent periodic overhauling periods.

Also the proper study of contact stresses in bearings will help in reducing the bearing failures.

\section{REFERENCES}

1. Hamrock, Bernard J., and William J. Anderson.,"Rolling-element bearings",

2. .National Aeronautics and Space Administration, Vol. 1105, 1983.

3. Schwarz, Vilmar Arthur, "Experimental studies of the thermal behaviour of a tapered roller bearing assembly", Proceedings of the 11th Brazilian Congress of Thermal Sciences and Engineering, 2006.

4. Kayal1, Yusuf, Ismail Ucun, and KubilayAslantaş, "Contact fatigue failure of a tapered roller bearing used in a lorry wheel", Journal of failure analysis and prevention 9.3,pp.288-294. (2009)

5. Ebert, Franz-Josef, "Fundamentals of design and technology of rolling 
element bearings", Chinese Journal of Aeronautics 23.1, 123-136, (2010):

6. Yongqi, Zhang, "Analysis of Stress and Strain of the Rolling Bearing by FEA method", Physics Procedia 24 19-24 (2012)

7. Guo, Yi, and Robert G. Parker, "Stiffness matrix calculation of rolling element bearings using a finite element/contact mechanics model,"Mechanism and Machine Theory 51, 32-45, (2012).

8. TANG Zhaopinga, SUN Jianping, "The Contact Analysis for Deep Groove Ball Bearing Based on ANSYS",Defence Technology 9, 229e236, (2013)

9. R.K. Upadhyay, L.A. Kumaraswamidhas, Md.SikandarAzam, "Rolling element bearing failure analysis: A case study", Case Studies in Engineering Failure Analysis 1, 15-17, (2013)

10. Yan-shuang WANG, Qian-qian YUAN, "Contact Force Distribution and Static Load- carrying Capacity of Large Size Double Row Four-point Contact Ball Bearing",Procedia Engineering 64, 1582 - 1591, ( 2013 )

11. H. Saruhan, S. Sardemir, A. Çiçek and Uygur,"Vibration Analysis of Rolling Element Bearings Defects", Vol.12, June2014

12. Shah, Dipen S., and Vinod N. Patel, "A Review of Dynamic Modeling and Fault Identifications Methods for Rolling Element Bearing", Procedia Technology 14, 447-456, (2014).

13. M. Prem Kumar, Dr.C.J.Rao, "Structural and Thermal Analysis on a Tapered Roller Bearing", IJISET International Journal of Innovative Science, Engineering \& Technology, Vol. 2 Issue 1, January 2015.

14. Graça, B. M., A. J. V. Campos, and J. H. O. Seabra, "taper roller bearings lubricated with bio-greases",Revista da Associação Portuguesa de Análise Experimental de Tensões ISSN 1646:
7078.

15. CTRB manual Railway Workshop, Kurduwadi.

16. http://www.nbcbearings.com/product/cart iridge- tapered-roller-bearings 